\title{
The first report of the qnrB19, qnrS1 and aac(6')-Ib-cr genes in urinary isolates of ciprofloxacin-resistant Escherichia coli in Brazil
}

\author{
Magna Cristina Paiva', Andréa Maria Amaral Nascimento², Ilana Lopes Baratella Cunha Camargo ${ }^{3}$, \\ Cláudia Iracema Lima-Bittencourt ${ }^{2}$, Regina Maria Drummond Nardi+ \\ 'Departamento de Microbiologia 2Departamento de Biologia Geral, Instituto de Ciências Biológicas, Universidade Federal de Minas Gerais, \\ Av. Antônio Carlos 6627, 31270-901 Belo Horizonte, MG, Brasil 'Laboratório de Epidemiologia e Microbiologia Molecular, \\ Grupo de Cristalografia, Instituto de Física de São Carlos, Universidade de São Paulo, São Carlos, SP, Brasil
}

In this study, we investigated the presence of plasmid-mediated quinolone resistance (PMQR) genes among 101 ciprofloxacin-resistant urinary Escherichia coli isolates and searched for mutations in the quinolone-resistancedetermining regions (QRDRs) of the DNA gyrase and topoisomerase IV genes in PMQR-carrying isolates. Eight isolates harboured the qnr and aac(6')-Ib-cr genes (3 qnrS1, 1 qnrB19 and 4 aac(6')-Ib-cr). A mutational analysis of the QRDRs in qnr and aac(6')-Ib-cr-positive isolates revealed mutations in $\mathrm{gyrA}, \operatorname{parC}$ and parE that might be associated with high levels of resistance to quinolones. No mutation was detected in gyrB. Rare gyrA, parC and parE mutations were detected outside of the QRDRs. This is the first report of qnrB19, qnrS1 and aac(6')-Ib-cr-carrying E. coli isolates in Brazil.

Key words: qnrS1 - qnrB19 - aac(6')-Ib-cr

Escherichia coli is a common cause of communityacquired urinary tract infections (CA-UTIs). Quinolones have become the most frequently prescribed antimicrobials worldwide due to their broad-spectrum antimicrobial activity (Yang et al. 2010). However, in the last few decades, an increase in quinolone resistance has been documented among human and veterinary isolates of E. coli. Quinolone resistance among Enterobacteriaceae originally occurred due to chromosomal mutations in the quinolone-resistance-determining regions (QRDRs) of the $g y r A$ and $g y r B$ genes, which encode the gyrase A and B subunits, respectively and the $\operatorname{parC}$ and parE genes, which encode topoisomerase IV subunits (Hernández et al. 2011). In addition to the chromosomal mutations in the QRDRs, plasmid-mediated quinolone resistance (PMQR) determinants may also reduce the levels of quinolone susceptibility; these elements were first described in 1998 (Martinez-Martinez et al. 1998, Robicsek et al. 2006a, Hernández et al. 2011). Over the last several years, different PMQR gene variants have been described in different locations worldwide. Nevertheless, few studies of PMQR genes have been conducted in Brazil. The first PMQR determinants were described by Castanheira et al. (2007) (qnrA) and by Minarini et al. (2008) $(q n r B)$. The overuse of quinolones in the clinical setting may lead to treatment failure and a public health risk; consequently, a better understanding of

Financial support: CNPq (475024/2009-5), FAPEMIG (01401-10), Pró-Reitoria de Pesquisa/UFMG

AMAN is a CNPq fellow.

+ Corresponding author: nardi@icb.ufmg.br

Received 11 October 2011

Accepted 15 February 2012
$\mathrm{PMQR}$ genes is of fundamental importance. Therefore, in this study, we investigated the presence of the qnrA, qnrB, $q n r S$ and $a a c\left(6^{\prime}\right)-I b-c r$ genes in a sample of ciprofloxacinresistant $E$. coli isolates from women with CA-UTIs.

A total of 101 ciprofloxacin-resistant $E$. coli isolates collected from the urine of women with clinical and laboratory diagnoses of CA-UTI between May-November 2009 in Belo Horizonte, Minas Gerais, Brazil, were investigated. Only one isolate per patient was included. These isolates were identified using an automated VITEK 2 microbial identification system, version 04.02 (bioMérieux), according to the manufacturer's instructions. This study was approved by the Ethical Committee of the Federal University of Minas Gerais (178/09).

The minimum inhibitory concentration (MICs) of nalidixic acid, ciprofloxacin, ofloxacin, norfloxacin and levofloxacin (Sigma-Aldrich) for all $a a c\left(6^{\prime}\right)-I b-c r$ and $q n r$-positive isolates were determined using the agar dilution method (CLSI 2009). Screening for extended-spectrum beta-lactamase (ESBL) production was performed with the broth microdilution method using an automated VITEK 2 system, version 04.02 (bioMérieux), according to the CLSI (2009) guidelines.

All isolates were screened for the presence of the $q n r A, q n r B, q n r S$ and $a a c\left(6^{\prime}\right)-I b-c r$ genes using previously described primers and amplification conditions (Park et al. 2006, Robicsek et al. 2006b). The QRDRs of the chromosomal genes were amplified only from the $a a c\left(6^{\prime}\right)-I b-c r$ and $q n r$-positive isolates using previously described primers and conditions (Park et al. 2006, Morgan-Linnell et al. 2009). The PCR products were sequenced with a MegaBACE 1000 capillary sequencer. The predicted amino acid sequences of GyrA, GyrB, ParC and ParE were analysed to identify putative amino acid changes with respect to the wild-type protein sequences from E. coli K12 MG 1655 (GenBank accession 49175990). The nucleotide sequences obtained have been 
deposited in GenBank under the following accessions: qnrB19 (JF923528), aac(6')Ib-cr (JF923529-JF923532), qnrSl (JF923533-JF923535), gyrA (JN565698-JN565702 and JN415087-JN415089), gyrB (JN565703-JN565710), parC (JN565711-JN565713 and JN657512-JN657516) and parE (JN565714-JN565721).

Eight of the 101 isolates evaluated (7.9\%) harboured PMQR genes. Among the qnr-positive isolates, three contained $q n r S 1$ and one contained $q n r B 19$. It should be noted that no isolate harboured the $q n r A$ gene, although the detection of this gene in Brazilian isolates was previously described by Castanheira et al. (2007). Few qnrS1 and qnrB19-positive $E$. coli isolates have been reported since 2008 and most of these isolates were qnrB19-positive isolates from South America (Deepak et al. 2009). In Brazil, the detection of the qnrAl gene in E. coli (Castanheira et al. 2007) and of qnrB2 and qnrB8 genes in other Enterobacteriaceae (Minarini et al. 2008) has been described previously and the $q n r B 19$ gene was recently detected for the first time in Salmonella isolated from poultry (Ferrari et al. 2011). Furthermore, four isolates in our study were $a a c\left(6^{\prime}\right)-I b-c r$-positive. Although the $a a c\left(6^{\prime}\right)-I b-c r$ gene appears to be more prevalent overall than any of the $q n r$ genes (Morgan-Linnell et al. 2009), we detected these genes at the same frequency in the present study. These findings conflict with the results of with previous studies, which indicated that $q n r B$ was the most widespread PMQR in Brazil (Minarini et al. 2008).

The analysis of the qnrS1, qnrB19 and aac(6')-Ib-cr sequences revealed $100 \%$ identity to the reported qnrS1 sequence from the IncN plasmid from the Salmonella enterica subsp. enterica strain 382/03 (GenBank accession HQ214119.1); $99 \%$ identity to the qnrB19 sequence from the E. coli plasmid p013.1 IncR (GenBank accession HM146784.1) and $100 \%$ identity to the $a a c\left(6^{\prime}\right)-I b-$ cr sequence from the Shigella dysenteriae strain DS-505 (GenBank accession HQ166949.1), respectively.

Sequence analysis of the chromosomal QRDR revealed mutations in the gyrA, parC and parE genes. No gyr $B$ mutation was detected. Most isolates exhibited double mutations in GyrA and single mutations in ParC and ParE (Table). Our results are in agreement with those of previous works, which showed that substitutions at S83 and D87 in gyrA and S80 in parC are common and lead to a high level of quinolone resistance (Hopkins et al. 2005, Sorlozano et al. 2007). Additionally, rare mutations outside of the GyrA, ParC and ParE QRDRs were detected (Table); among these, only S458 in parE had been reported previously (Sorlozano et al. 2007, Moon et al. 2010, Bansal \& Tandon 2011). This mutation was originally reported in Spain (Sorlozano et al. 2007) and was identified at a high frequency in $E$. coli isolates recovered in Delhi, India (Bansal \& Tandon 2011). There have been few reports of uncommon mutations outside QRDRs (Friedman et al. 2001, Lindgren et al. 2003, Sorlozano et al. 2007) and the effects of such mutations on quinolone susceptibility should be studied further.

The high observed MICs for quinolones (Table) were likely a consequence of mutations in the chromosomal QRDRs associated with PMQR genes. Previous works also suggested that PMQR and chromosomal resistance

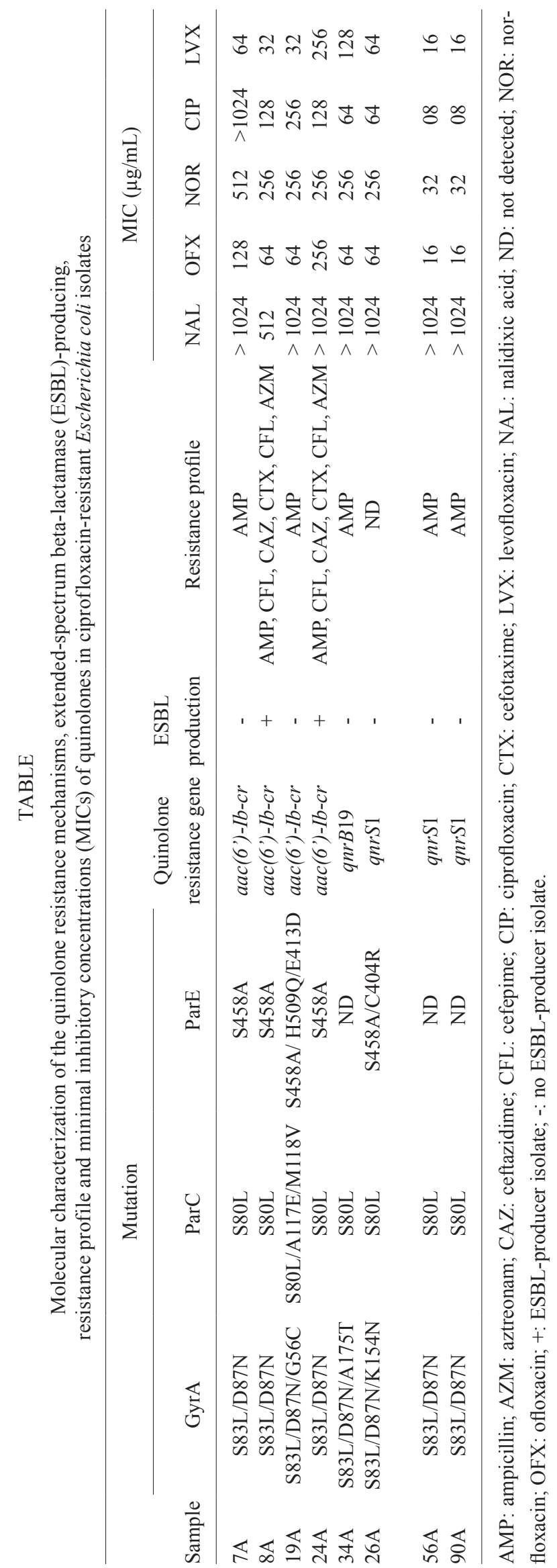


mechanisms are additive and can enhance the quinolone resistance of clinical isolates (Martínez-Martínez et al. 2003, Rodríguez-Martínez et al. 2011). Furthermore, it should be noted that PMQR genes may facilitate the emergence of quinolone resistance, which would have therapeutic implications (Rodríguez-Martínez et al. 2011).

Recently, the association of aac(6')- $\mathrm{Ib}-\mathrm{cr}$ with genes encoding the beta-lactamase CTX-M-15 or other ESBLs has been reported (Pitout et al. 2008). Therefore, we considered it important to analyse the ESBL production of PMQR-positive E. coli isolates. Only two of the eight PMQR-positive isolates screened produced ESBLs and both of these isolates were positive for $a a c\left(6^{\prime}\right)-I b-c r$. To verify the horizontal mobility and potential capacity for the spreading of these genes, conjugation (Yang et al. 2008) and transformation (Sambrook \& Russell 2001) experiments were conducted. However, the genes did not appear to be transferable by transformation or conjugation.

This article describes the first $E$. coli isolates in Brazil harbouring the qnrS1, qnrB19 and $a a c\left(6^{\prime}\right)-\mathrm{Ib}$-cr genes. The $a a c\left(6^{\prime}\right)-I b$-cr-positive isolates, which also produced ESBLs, are of particular clinical concern.

\section{ACKNOWLEDGEMENTS}

To the Patologia Clínica Geraldo Lustosa, for supplying the isolates, and to Dr Luciene AR Minarini and Dr Ana C Gales, for sending the control strains to this study.

\section{REFERENCES}

Bansal S, Tandon V 2011. Contribution of mutations in DNA gyrase and topoisomerase IV genes to ciprofloxacin resistance in Escherichia coli clinical isolates. Int J Antimicrob Agents 37: 253-255.

Castanheira M, Pereira AS, Nicoletti AG, Pignatari ACC, Barth AL, Gales AC 2007. First report of plasmid-mediated qnrAl in a ciprofloxacin-resistant Escherichia coli strain in Latin America. Antimicrob Agents Chemother 51: 1527-1529.

CLSI - Clinical and Laboratory Standards Institute 2009. Performance standards for antimicrobial disk susceptibility testing, 19 th informational supplement, CLSI, Wayne, $10 \mathrm{pp}$.

Deepak RN, Koh TH, Chan KS 2009. Plasmid-mediated quinolone resistance determinants in urinary isolates of Escherichia coli and Klebsiella pneumoniae in a large Singapore Hospital. Ann Acad Med Singapore 38: 1070-1073.

Ferrari R, Galiana A, Cremades R, Rodriguez JC, Magnani M, Tognim MCB, Oliveira TCRM, Royo G 2011. Plasmid-mediated quinolone resistance by genes qnrA1 and qnrB19 in Salmonella strains isolated in Brazil. J Infect Dev Ctries 5: 496-498.

Friedman S, Lu T, Drlica K 2001. Mutation in the DNA gyrase A gene of Escherichia coli that expands the quinolone resistance-determining region. Antimicrob Agents Chemother 45: 2378-2380.

Hernández A, Sánchez MB, Martinéz J 2011. Quinolone resistance: much more than predicted. Front Microbiol 2:1-6.

Hopkins KL, Davies RH, Threlfall EJ 2005. Mechanisms of quinolone in Escherichia coli and Salmonella: recent developments. Int $J$ Antimicrob Agents 25: 358-373.
Lindgren PK, Karlsson A, Hughes D 2003. Mutation rate and evolution of fluoroquinolone resistance in Escherichia coli isolates from patients with urinary tract infections. Antimicrob Agents Chemother 47: 3222-3232.

Martinez-Martinez L, Garcia I, Ballesta S, Benedi VJ, HernándezAllés S, Pascual A 1998. Energy dependent accumulation of fluoroquinolones in quinolone resistant Klebsiella pneumoniae strains. Antimicrob Agents Chemother 42: 1850-1852.

Martínez-Martínez L, Pascual A, Garcia I, Tran J, Jacoby GA 2003. Interation of plasmid and host quinolone resistance. J Antimicrob Chemother 51: 1037-1039.

Minarini LAR, Poirel L, Cattoir V, Darini ALC, Nordmann P 2008. Plasmid-mediated quinolone resistance determinants among enterobacterial isolates from outpatients in Brazil. J Antimicrob Chemother 62: 474-478.

Moon DC, Seol SY, Gurung M, Jin JS, Choi CH, Kim J, Lee YC, Cho DT, Lee JC 2010. Emergence of a new mutation and its accumulation in the topoisomerase IV gene confers high level of resistance to fluoroquinolones in Escherichia coli isolates. Int J Antimicrob Agents 35: 76-79.

Morgan-Linnell SK, Boyd LB, Steffen D, Zechiedrich L 2009. Mechanisms accounting for fluoroquinolone resistance in Escherichia coli clinical isolates. Antimicrob Agents Chemother 53: 235-242.

Park CH, Robicsek A, JacobyGA, Sahm D, Hooper DC 2006. Prevalence in the United States of $a a c\left(6^{\prime}\right) I b-c r$ enconding a ciprofloxacin-modifying enzyme. Antimicrob Agents Chemother 50: 3953-3955.

Pitout JD, Wei Y, Church DL, Gregson DB 2008. Surveillance for plasmid-mediated quinolone determinants in Enterobacteriacea within the Calgary Health Region, Canada: the emergence of aac(6')-Ib-cr. J Antimicrob Chemother 61: 999-1002.

Robicsek A, Strahilevitz J, Jacoby GA, Macielag M, Abbanat D, Park $\mathrm{CH}$, Bush K, Hooper DC 2006a. Fluoroquinolone-modifying enzyme: a new adaptation of a common aminoglycoside acetyltransferase. Nat Med 12: 83-88.

Robicsek A, Strahilevitz J, Sham DF, Jacoby GA, Hooper DC 2006 b. $q n r$ prevalence in ceftazidime-resistant Enterobacteriaceae isolates from the United States. Antimicrob Agents Chemother 50: $2872-2874$.

Rodríguez-Martínez JM, Cano ME, Velasco C, Martínez-Martínez L, Pascual A 2011. Plasmid-mediated quinolone resistance: an update. J Infect Chemother 17: 149-182.

Sambrook J, Russell DW 2001. Plasmid and their usefulness in molecular cloning. In Molecular cloning: a laboratory manual, Cold Spring Harbor, New York, p. 118-122.

Solorzano A, Gutierrez J, Jimenez A, Luna JD, Martinéz JL 2007. Contribution of a new mutation in parE to quinolone resistance in extended-spectrum- $\beta$-lactamase-producing Escherichia coli isolates. J Clin Microbiol 45: 2740-2742.

Yang H, Chen H, Yang Q, Chen M, Wang H 2008. High prevalence of plasmid-mediated quinolone resistance genes $q n r$ and $a a c\left(6^{\prime}\right) \mathrm{Ib}-\mathrm{cr}$ in clinical isolates of Enterobacteriaceae from nine teaching hospitals in China. Antimicrob Agents Chemother 52: 4268-4273.

Yang J, Luo Y, Li J, Ma Y, Hu C, Jin S, Ye L, Cui S 2010. Characterization of clinical Escherichia coli isolates from China containing transferable quinolone resistance determinants. $J$ Antimicrob Chemother 65: 453-459. 